\title{
Types of fat intake and body mass index in a Mediterranean country
}

Carlos A González 1,* , Guillem Pera ${ }^{1}$, José R Quirós², Cristina Lasheras², María José Tormo ${ }^{3}$, Mauricio Rodriguez ${ }^{4}$, Carmen Navarro ${ }^{3}$, Carmen Martinez ${ }^{4}$, Miren Dorronsoro ${ }^{5}$, María Dolores Chirlaque ${ }^{3}$, José M Beguiristain ${ }^{5}$, Aurelio Barricarte ${ }^{6}$, Pilar Amiano 5 and Antonio Agudo ${ }^{1}$

${ }^{1}$ Institut Catalàn d'Oncologia, Barcelona, Spain: ${ }^{2}$ Consejería de Sanidad y Servicios Sociales de Asturias, Oviedo, Spain: ${ }^{3}$ Consejería de Sanidad y Política Social, Murcia, Spain: ${ }^{4}$ Escuela Andaluza de Salud Pública, Granada, Spain: ${ }^{5}$ Dirección de Salud de Gipúzkoa, San Sebastián, Spain: ${ }^{6}$ Departamento de Salud de Navarra, Pamplona, Spain

Submitted 14 September 1999: Accepted 7 January 2000

\begin{abstract}
Background: Although the fatty acid fractions provide similar metabolizable energy, the type of dietary fat consumed could be relevant to the development of obesity. Objective: To investigate the relationship between body mass index (BMI), obesity and the consumption of different types of fat and olive oil in a Mediterranean country with high prevalence of obesity, and high intake of monounsaturated fatty acids (MUFA) and olive oil.

Subjects: The study was carried out in Spain among 23289 women and 14374 men, aged 29-69 years, who were participants of a large European prospective cohort.

Methods: Information on usual food intake was collected by interviewers by means of a dietary history questionnaire. The association between obesity $\left(\mathrm{BMI} \geqslant 30 \mathrm{~kg} \mathrm{~m}^{2}\right.$ ), dietary fat, other dietary patterns and other non-dietary factors were tested using multilinear regression analysis. The ratio of reported energy intake to energy requirement was used as an estimation of dietary underreporting.

Results: The association between fatty acid fractions intake (saturated fatty acids (SFA) in women, and MUFA and polyunsaturated fatty acids (PUFA) in both sexes) and BMI was very weak, accounting for less than $1 \%$ of variance. All dietary and non-dietary variables accounted for $21 \%$ of variance in the measurement of BMI in women and only $6.7 \%$ of variance in men. Estimated underreporting of energy intake was $17.5 \%$ in obese women and $5.5 \%$ in obese men.

Conclusions: The association between consumption of specific types of dietary fat, olive oil and obesity in Spain is not very important. However, because of the crosssectional design and some level of underreporting of energy intake observed in overweight subjects and overreporting in underweight subjects, systematic bias cannot be completely discarded.
\end{abstract}

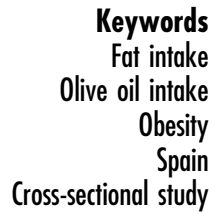

Keywords

il intake

besity

Cross-sectional study
Obesity is increasing in the USA ${ }^{1}$ and in most European countries $^{2}$, notably among middle-aged women, particularly from Mediterranean and Eastern European countries $^{3}$. In Spain ${ }^{4}$, in a representative sample of the general population from a Mediterranean region, the prevalence of obesity in the group aged 50-64 years was 38.4\% in women and $25.2 \%$ in men. Consumption of energy in Spain is high, as is the intake of total and monounsaturated fat, mainly from olive oil, which is an important source (8\%) of total energy intake 5 .

Although the aetiology of obesity is still unclear ${ }^{6}$, several factors including genetic susceptibility, energy metabolism, dietary intake and other social behaviours, are believed to play a role in its development and progression. The prevalence of obesity is usually inversely associated with physical activity and educational level ${ }^{2}$ and it is considered that modern inactive lifestyles are at least as important as diet in the aetiology of obesity, possibly representing the dominant factor ${ }^{7}$. Metabolic changes associated with menopause may also be important in women ${ }^{8}$.

Dietary fat is the most energy-dense macronutrient and high fat intake, when associated with overconsumption of calories, has been considered to be an important factor in the development of obesity. It has been suggested that because fat provides a greater palatability to foods and 
possesses a lower satiating power than carbohydrate and protein, a diet rich in fat may increase energy intake? However, it has been shown that the energy density, but not the fat content of the foods, affected total energy intake at meals in both lean and obese women ${ }^{10}$. Clinical evidence shows that weight loss is positively correlated to the reduction in dietary fat intake ${ }^{9}$. Nevertheless, despite some ecological, cross-sectional and prospective studies supporting this concept, the evidence is not considered to be conclusive ${ }^{11-13}$. Resuts from randomized trials are also inconsistent. Although a recent meta-analysis of dietary trials ${ }^{14}$ concluded that a $10 \%$ reduction in the percentage of energy from fat would reduce body weight by $16 \mathrm{~g} /$ day, this result was considered unconvincing because it was based mainly on short-term studies while most long-term controlled trials have not shown a prolonged weight reduction ${ }^{15}$.

When calories from fat are restricted they are replaced by calories from carbohydrates which could explain why the prevalence of obesity has increased in the USA ${ }^{13}$ and Britain $^{7}$ despite the fact that energy intake from fat has declined. It also seems that the dietary fat: carbohydrate ratio might be of particular importance in individuals with an inherited susceptibility to obesity ${ }^{16}$. The recent debate ${ }^{17}$ on the advantages and disadvantages of a low-fat, highcarbohydrate diet regarding cancer, coronary heart disease and obesity shows that the problem is still open. Moreover, investigating the specific role of each type of fat separately, instead of concentrating on total fat reduction, has been recommended. The type of dietary fat consumed could be relevant to the development of obesity ${ }^{11,18,19}$. Although the fatty acid fractions provide similar metabolizable energy, satiating power and/or storing power might differ according to the specific type of fat.

The main purpose of this paper is to investigate the relationship between specific fatty acid fractions intake (SFA, MUFA, PUFA), olive oil consumption, and BMI and obesity in middle-aged women and men from five areas of the north and south of Spain.

\section{Methods}

\section{Population}

The study was carried out in the Spanish cohort of the European Prospective Investigation into Cancer and Nutrition (EPIC), a large cohort study ${ }^{20}$ that is being carried out in nine European countries (Denmark, France, Germany, Great Britain, Greece, Italy, the Netherlands, Spain and Sweden). The population studied in Spain included a total of 25814 women and 15635 men aged 29-69 years, recruited from October 1992 to July 1996 in three regions of the north (Navarra, Asturias and Gipuzkoa) and two regions of the south (Murcia and Granada). Participants were healthy volunteers (mainly blood donors), with different social and educational levels, who received an invitation and agreed (approximately between $50 \%$ and $60 \%$ ) to participate in the EPIC study. Subjects (1133 women and 337 men) who reported having been following a slimming diet were excluded for the analysis.

\section{Dietary habits}

Information on each subject's habitual food intake during the previous year was collected by trained interviewers using a computerized version of a diet history questionnaire $^{21}$. The dietary questionnaire which had previously been evaluated for validity and repeatability ${ }^{22-24}$ was structured by meals (breakfast, mid morning, lunch, mid afternoon, dinner and late evening snacks). Any food consumed at least twice a month was recorded. Portion intake was quantified by natural units, geometric figures and by a manual of 35 sets of photographs of simple foods,mixed foods and drinks. Each diet history interview lasted about 40-50 min. Energy and nutrient intake was estimated using a conversion table in a computerized database $^{25}$ that contained more than 800 simple foods, recipies and beverages specially compiled for the EPIC study in Spain.

\section{Antbropometric measurements}

Height and weight were taken following a standard protocol $^{26}$ by the same previously trained interviewers. Each subject was measured barefoot wearing light clothes. Height (to the nearest $0.1 \mathrm{~cm}$ ) was measured using a movable stadiometer. Weight was measured to the nearest $100 \mathrm{~g}$ after urination, using an electronic, regularly calibrated weighing machine. BMI was calculated as weight in kilograms divided by the square height in metres. In order to obtain comparative data, BMI was categorized using the same levels that were used in a study on prevalence of obesity in Spain, in a representative sample of the general population ${ }^{4}$. A BMI of $<20 \mathrm{~kg} \mathrm{~m}^{2}$ was considered 'underweight', $20.00-24.99 \mathrm{~kg} \mathrm{~m}^{2}$ was considered 'normal', $25.00-29.99 \mathrm{~kg} \mathrm{~m}^{2}$ was considered 'overweight' and $\geqslant 30.00 \mathrm{~kg} \mathrm{~m}^{2}$ was considered 'obese'.

\section{Physical activity and other information}

This information was taken by interview using a general questionnaire which included sections on socioeconomic status, past and current physical activity, menstrual status and past and current consumption of tobacco. Current job was classified into sedentary work, standing work, manual work and heavy manual work. Leisure activities included questions on time spent during the last year (in hours by week in summer and winter time) walking, cycling, gardening, practising hobbies, sports and housework. Total leisure activities were computed as the sum of the mean number of hours in summer and winter of all activities excluding sport and housework, which were considered separately. The reproducibility and validity of 
the EPIC physical activity questions were estimated in a previous pilot study ${ }^{27}$.

Socioeconomic status was measured by means of the highest completed educational level obtained, which was classified into five categories, from uncompleted primary school to completed university. Consumption of any type of tobacco was classified into four categories: never smokers, recent ex-smokers (less than 3 years), long exsmokers (3 or more years) and current smokers. Menopausal status in women was classified into three groups: still regular menstrual cycle, recent menopause and long time (more than 1 year) since last regular menstrual cycle.

\section{Estimation of underreporting}

Calculation of basal metabolic rate (BMR) using Schofield equations $^{28}$, based on height and weight by age and sex, was used to estimate energy requirements (ER). Using a physical activity level (PAL) of 1.55 (frequently used for western countries) $\mathrm{ER}=\mathrm{BMR} \times 1.55$. Observed energy intake (EI) divided by ER gives an estimate of underreporting of energy in our study. The EI divided by BMR gives an estimate of the PAL value actually observed in our population.

\section{Statistical analysis}

The associations between obesity (measured through the BMI), dietary fat, other dietary factors and other potential variables were tested using univariate and multivariate techniques. Analysis of variance was used to ascertain mean differences of the studied variables between the BMI groups without control for the potential confounders. Multilinear regression analysis was used to ascertain the relationship between specific types of dietary fat consumption (as independent variables) and BMI (as dependent variable) after differences in other selected variables such as age, total energy intake, intake of other macronutrients, physical activity, educational level, menopausal status, number of births and tobacco smoking were adjusted for. Subjects who had missing values in at least one of the variables needed for this analysis (2316 subjects) were excluded, so it was finally based on 23289 women and 14374 men.

\section{Results}

Table 1 shows some general features of the study population. BMI and prevalence of obesity increased in both sexes with age and decreased with increasing educational levels and increasing levels of sports and leisure time physical activities. In women, BMI increased with the number of births, menopausal status, levels of housework, work activity and decreased with smoking status. In men, slight differences were observed with regard to work activity and smoking.
Selected patterns of dietary intake according to BMI in women are presented in Table 2. A weak decrease in the intake of energy, total fat and fatty acid fractions (SFA, MUFA, PUFA) was associated with an increase in BMI. A decrease in carbohydrate, sweets and alcohol intake was also associated with an increase of BMI. Similar results were found using absolute ( $\mathrm{g} /$ day) or relative (\% of total calories) values, excepting calories from olive oil, which was not associated with BMI.

In men (Table 3) a decrease in energy intake was associated with an increase in BMI. Absolute (g/day) intake of total fat, SFA, PUFA and olive oil were not associated with BMI. A weak increase in the relative intake of total fat and MUFA, as a proportion of total calorie intake, was associated with an increase in BMI. Alcohol intake was also positively associated with obesity in men. The Pearson correlation coefficients between BMI and total energy intake were -0.12 in women and -0.02 in men (data not shown).

Multilinear regression models for significant factors associated with BMI by gender are shown in Table 4. In women, after adjusting for non-dietary variables associated with BMI, different types of fat intake (SFA, MUFA and PUFA) expressed as a percentage of total energy were significant predictors of BMI, but account for less than 1\% of the variance in the measurement of BMI. Association between BMI and energy from total fat, MUFA, PUFA and olive oil was positive but the association with SFA and carbohydrate was negative. All dietary and non-dietary variables account for $21.0 \%$ of variance $\left(R^{2}=0.21\right)$ in the measurement of BMI. The percentage of explained variance from different models remained approximately the same when energy from type of fatty acid was replaced by energy from total fat, energy from olive oil or energy from carbohydrate. A similar pattern was observed in men: after adjustment for non-dietary variables associated with BMI, the association of different types of fat intake and BMI is also very weak, accounting for less than $1 \%$ of variance. All diet and non-dietary variables account for only $6.7 \%$ of variance $\left(R^{2}=0.067\right)$.

\section{Discussion}

An important debate has arisen in recent years about the role of dietary fat intake in the development of obesity ${ }^{13-15}$. At this stage it seems that there is no conclusive evidence that under isoenergetic conditions fat intake promotes the development of obesity more than other macronutrients ${ }^{12}$. Previous cross-sectional studies have found a positive association between dietary fat intake and $\mathrm{BMI}^{29-31}$, but one study ${ }^{32}$ did not find any association. Another study ${ }^{33}$ found that the percentage of calories from lipids was positively correlated with fat mass (measured by densitometry) but not with body weight. Another study ${ }^{34}$ observed an association between energy from fat and BMI but not with percentage of body fat. Some studies 
Table 1 Socioeconomic, demographic and behavioural characteristics of women and men participants in the study

\begin{tabular}{|c|c|c|c|c|c|c|c|c|}
\hline & & & Women & & & & Men & \\
\hline & $n$ & $\%$ & Mean (SD) & $\%$ obese & $n$ & $\%$ & Mean (SD) & $\%$ obese \\
\hline Age (years) & & & & & & & & \\
\hline $29-44$ & 9137 & 39.2 & $26.39(4.36)$ & 17.4 & 3911 & 27.2 & $27.81(3.37)$ & 22.2 \\
\hline $45-54$ & 8416 & 36.1 & $28.66(4.58)$ & 34.0 & 6378 & 44.4 & $28.40(3.25)$ & 28.1 \\
\hline $55-69$ & 5736 & 24.6 & $29.87(4.52)$ & 44.4 & 4085 & 28.4 & $28.90(3.64)$ & 34.3 \\
\hline Education level & & & & & & & & \\
\hline None & 9383 & 40.3 & $29.87(4.62)$ & 44.6 & 3736 & 26.0 & $29.15(3.73)$ & 36.9 \\
\hline Primary & 9117 & 39.1 & 27.67 (4.39) & 25.5 & 5419 & 37.7 & $28.57(3.33)$ & 30.1 \\
\hline Secondary/high school & 2550 & 10.9 & $25.69(3.89)$ & 12.4 & 3023 & 21.0 & $27.88(3.15)$ & 22.3 \\
\hline University & 2239 & 9.6 & $24.84(3.73)$ & 7.7 & 2196 & 15.3 & $27.28(3.06)$ & 17.3 \\
\hline Work activity & & & & & & & & \\
\hline Sedentary & 3059 & 13.1 & $26.16(4.63)$ & 16.7 & 5160 & 35.9 & 28.27 (3.39) & 27.9 \\
\hline Standing & 19746 & 84.8 & $28.36(4.64)$ & 32.1 & 5118 & 35.6 & $28.36(3.31)$ & 27.7 \\
\hline Manual/heavy manual & 484 & 2.1 & 28.34 (4.92) & 32.4 & 4096 & 28.5 & $28.55(3.59)$ & 29.4 \\
\hline Housework (h week ${ }^{-1}$ ) & & & & & & & & \\
\hline$\leqslant 7$ & 1616 & 6.9 & $25.98(4.43)$ & 15.6 & 13042 & 90.7 & $28.44(3.42)$ & 28.7 \\
\hline $7-21$ & 4984 & 21.4 & $27.19(4.64)$ & 23.6 & 1168 & 8.1 & $27.86(3.42)$ & 24.0 \\
\hline$>21$ & 16689 & 71.7 & $28.53(4.65)$ & 33.4 & 164 & 1.1 & $27.62(3.34)$ & 21.3 \\
\hline Sport $\left(\mathrm{h} \mathrm{week}^{-1}\right.$ ) & & & & & & & & \\
\hline 0 & 18162 & 78.0 & $28.52(4.76)$ & 33.6 & 10178 & 70.8 & $28.68(3.43)$ & 31.9 \\
\hline $0-3$ & 2808 & 12.1 & $26.59(4.08)$ & 18.2 & 1979 & 13.8 & $27.75(3.05)$ & 20.5 \\
\hline$\geqslant 3$ & 2319 & 10.0 & $26.28(4.08)$ & 16.3 & 2217 & 15.4 & $27.57(3.50)$ & 18.4 \\
\hline Other leisure activities ( $\mathrm{h}$ & & & & & & & & \\
\hline$<1$ & 1501 & 6.4 & $28.51(5.01)$ & 33.6 & 917 & 6.4 & $28.96(3.75)$ & 34.8 \\
\hline $1-7$ & 11874 & 51.0 & $28.21(4.79)$ & 31.3 & 5274 & 36.7 & $28.43(3.38)$ & 28.6 \\
\hline$>7$ & 9914 & 42.6 & $27.83(4.53)$ & 28.1 & 8183 & 56.9 & $28.28(3.40)$ & 27.3 \\
\hline Smoking & & & & & & & & \\
\hline Never smoker & 16641 & 71.5 & $28.87(4.65)$ & 36.0 & 4254 & 29.6 & $28.21(3.42)$ & 26.0 \\
\hline $\begin{array}{l}\text { Long ex-smoker } \\
\qquad \text { (>2 years ago) }\end{array}$ & 1651 & 7.1 & $26.21(4.33)$ & 15.9 & 3527 & 24.5 & $28.53(3.24)$ & 29.5 \\
\hline $\begin{array}{l}\text { Recent ex-smoker } \\
\text { (last } 2 \text { years) }\end{array}$ & 589 & 0.5 & $26.42(4.20)$ & 17.0 & 779 & 5.4 & $28.95(3.62)$ & 33.2 \\
\hline Current smoker & 4408 & 18.9 & $25.94(4.13)$ & 14.5 & 5814 & 40.4 & $28.34(3.50)$ & 28.5 \\
\hline Menopause & & & & & & & & \\
\hline With period & 13739 & 59.0 & $27.02(4.51)$ & 22.0 & & & & \\
\hline Recent menopause & 830 & 3.6 & $28.99(4.54)$ & 36.6 & & & & \\
\hline $\begin{array}{l}\text { Long time since } \\
\text { menopause }\end{array}$ & 8720 & 37.4 & $29.62(4.57)$ & 42.2 & & & & \\
\hline Parity & & & & & & & & \\
\hline 0 & 2534 & 10.9 & $26.46(4.48)$ & 19.4 & & & & \\
\hline 1 & 2324 & 10.0 & 27.04 (4.39) & 21.3 & & & & \\
\hline 2 & 8623 & 37.0 & $27.50(4.47)$ & 25.1 & & & & \\
\hline 3 & 5608 & 24.1 & $28.71(4.64)$ & 35.1 & & & & \\
\hline 4 or more & 4200 & 18.0 & $29.91(4.83)$ & 44.8 & & & & \\
\hline
\end{tabular}

have found that the percentage of body fat ${ }^{35}$ or BMI $^{30}$ was associated with energy from fat but not with total energy intake. In most of the studies, the association has been very weak (explaining only 3-6\% of variance) and other important factors such as intake of other macronutrients, physical activity and smoking, were not controlled ${ }^{11}$.

According to our results, in multilinear regression models, after adjusting for non-dietary variables associated with BMI, percentage of energy from total fat intake was positively associated with BMI in both sexes, although the association was very weak, accounting for less than $1 \%$ of variance in both sexes. Therefore this study, with a very high number of participants, in a country with high dietary fat intake, provides further evidence that energy from fat does not play an important role in the development of obesity.

Although the type of dietary fat consumed could be relevant to the development of obesity ${ }^{11}$, most studies have analysed the effect of total fat intake and little information is available regarding specific types of fat, particularly in Mediterranean countries where the prevalence of obesity and the consumption of olive oil is high and where diet is also characterized by a high energy intake with a high proportion of MUFA and PUFA. Evidence from animal studies ${ }^{18}$ shows that PUFA produce less body fat accumulation than beef tallow, while in 
Table 2 Dietary intake and anthropometric characteristics according to BMI in women (29-69 years)

\begin{tabular}{lccccc}
\hline & $\begin{array}{c}\text { Underweight } \\
(n=226), \\
\text { mean (SD) }\end{array}$ & $\begin{array}{c}\text { Normal } \\
(n=6327), \\
\text { mean (SD) }\end{array}$ & $\begin{array}{c}\text { Overweight } \\
(n=9737), \\
\text { mean (SD) }\end{array}$ & $\begin{array}{c}\text { Obese } \\
(n=6999), \\
\text { mean (SD) }\end{array}$ & $\begin{array}{c}\text { p-value } \\
(\mathrm{F} \mathrm{test)}\end{array}$ \\
\hline Energy (kcal) & $2151(623)$ & $2111(593)$ & $1989(572)$ & $1928(606)$ & 0.0001 \\
Fat intake (g) & $89.2(31.1)$ & $87.8(30.1)$ & $81.4(29.5)$ & $78.2(31.0)$ & 0.0001 \\
Energy \% fat & $37.0(5.9)$ & $37.2(6.0)$ & $36.4(6.3)$ & $36.0(6.2)$ & 0.0001 \\
SFA (g) & $32.6(13.5)$ & $31.3(12.9)$ & $28.6(12.5)$ & $27.2(12.8)$ & 0.0001 \\
Energy \% SFA & $13.4(3.3)$ & $13.2(3.3)$ & $12.7(3.4)$ & $12.4(3.3)$ & 0.0001 \\
MUFA (g) & $41.9(15.3)$ & $41.2(14.7)$ & $38.3(14.5)$ & $36.7(15.2)$ & 0.0001 \\
Energy \% MUFA & $17.5(3.6)$ & $17.5(3.7)$ & $17.2(3.9)$ & $17.0(4.0)$ & 0.0001 \\
PUFA (g) & $14.7(6.3)$ & $15.3(7.4)$ & $14.5(7.3)$ & $14.3(7.6)$ & 0.0001 \\
Olive oil (g) & $19.7(12.7)$ & $20.1(12.8)$ & $18.9(12.7)$ & $18.0(12.7)$ & 0.0001 \\
Energy \% olive oil & $8.5(5.3)$ & $8.8(5.3)$ & $8.7(5.6)$ & $8.6(5.7)$ & 0.2402 \\
Carbohydrate (g) & $252.2(81.0)$ & $243.2(76.9)$ & $230.8(72.4)$ & $226.1(73.5)$ & 0.0001 \\
Energy \% carbohydrate & $44.0(6.9)$ & $43.3(7.0)$ & $43.7(7.3)$ & $44.3(7.1)$ & 0.0001 \\
Sweets (g) & $75.5(68.3)$ & $69.9(58.5)$ & $60.6(57.2)$ & $55.2(55.5)$ & 0.0001 \\
Energy \% sweets & $12.6(9.4)$ & $12.1(8.8)$ & $10.9(8.8)$ & $10.2(8.7)$ & 0.0001 \\
Alcohol (g) & $5.7(9.5)$ & $5.6(9.7)$ & $4.9(9.6)$ & $3.4(8.3)$ & 0.0001 \\
Energy \% alcohol & $1.9(3.2)$ & $1.8(3.0)$ & $1.6(3.1)$ & $1.1(2.7)$ & 0.0001 \\
Anthropometrics & $42.8(7.0)$ & $44.4(7.5)$ & $48.8(8.2)$ & $51.5(7.9)$ & 0.0001 \\
Age (years) & $161.2(6.7)$ & $158.9(5.5)$ & $156.6(5.7)$ & $154.9(5.7)$ & 0.0001 \\
Height (cm) & $50.0(4.6)$ & $58.5(4.8)$ & $67.1(5.7)$ & $81.1(9.9)$ & 0.0001 \\
Weight (kg) & & & &
\end{tabular}

MUFA, monounsaturated fatty acids; PUFA, polyunsaturated fatty acids; SFA, saturated fatty acids.

${ }^{*}$ Sweets include sugar, honey, jam, chocolate, candy bars, paste, confetti/flakes, confectionery, ice-cream, cakes, pies, pastries, puddings and biscuits.

humans, using data from large cohorts in the USA ${ }^{19}$, a positive correlation was observed between BMI and SFA, oleic acid, linoleic acid and total energy intake, but coefficients were extremely low. On the other hand, animal- and vegetable-derived fat, respectively, were positively and negatively associated with weight change although total fat was not associated with this change. In our study we found that energy intake from SFA was inversely associated with BMI while energy from MUFA,
PUFA and olive oil was positively associated with BMI in both sexes, but the association was very weak for all types of dietary fat. Overall, the association between BMI and dietary habits was also very weak. Although the pattern of the association by sexes was very similar, the explained variability from dietary and non-dietary variables in men was much lower than in women ( $6 \%$ vs. $21 \%)$. A similar difference was observed regarding the impact of dietary intake and physical activity on weight change in adults ${ }^{36}$

Table 3 Dietary intake and anthropometric characteristics according to BMI in men (30-68 years)

\begin{tabular}{lccccc}
\hline & $\begin{array}{c}\text { Underweight } \\
(n=37), \\
\text { mean (SD) }\end{array}$ & $\begin{array}{c}\text { Normal } \\
(n=1983), \\
\text { mean (SD) }\end{array}$ & $\begin{array}{c}\text { Overweight } \\
(n=8293), \\
\text { mean (SD) }\end{array}$ & $\begin{array}{c}\text { Obese } \\
(n=4061), \\
\text { mean (SD) }\end{array}$ & $\begin{array}{c}\text { p-value } \\
(\mathrm{F} \mathrm{test)}\end{array}$ \\
\hline Energy (kcal) & $3025(852)$ & $2836(720)$ & $2792(732)$ & $2783(814)$ & 0.0152 \\
Fat intake (g) & $116.1(46.3)$ & $108.8(34.8)$ & $108.9(34.8)$ & $110.0(39.4)$ & 0.2460 \\
Energy \% fat & $33.7(7.1)$ & $34.4(5.9)$ & $35.1(6.0)$ & $35.5(6.1)$ & 0.0001 \\
SFA (g) & $40.1(18.1)$ & $36.9(14.3)$ & $36.4(14.3)$ & $36.2(15.7)$ & 0.1437 \\
Energy \% SFA & $11.6(3.3)$ & $11.6(3.0)$ & $11.7(3.0)$ & $11.6(2.9)$ & 0.7248 \\
MUFA (g) & $55.6(22.6)$ & $52.4(17.9)$ & $52.6(18.2)$ & $53.6(20.9)$ & 0.0152 \\
Energy \% MUFA & $16.2(3.6)$ & $16.6(3.7)$ & $17.0(3.9)$ & $17.3(4.1)$ & 0.0001 \\
PUFA (g) & $20.4(10.3)$ & $19.5(9.1)$ & $19.9(9.4)$ & $20.2(10.0)$ & 0.0627 \\
Olive oil (g) & $20.9(18.3)$ & $24.3(16.8)$ & $24.5(17.9)$ & $24.2(18.8)$ & 0.5730 \\
Energy \% olive oil & $6.2(5.1)$ & $7.9(5.2)$ & $8.1(5.7)$ & $8.1(6.0)$ & 0.0956 \\
Carbohydrate (g) & $339.6(89.3)$ & $314.0(93.2)$ & $296.7(90.9)$ & $283.8(89.8)$ & 0.0001 \\
Energy \% carbohydrate & $42.9(7.5)$ & $41.8(7.3)$ & $40.2(7.6)$ & $38.7(7.7)$ & 0.0001 \\
Sweets (g) & $65.9(45.7)$ & $64.7(58.3)$ & $56.2(53.3)$ & $49.0(52.7)$ & 0.0001 \\
Energy \% sweets & $8.7(6.0)$ & $8.6(7.3)$ & $7.7(6.7)$ & $6.6(6.5)$ & 0.0001 \\
Alcohol (g) & $28.2(32.0)$ & $27.9(29.1)$ & $31.1(32.4)$ & $34.9(35.8)$ & 0.0001 \\
Energy \% alcohol & $7.1(9.8)$ & $6.7(6.7)$ & $7.4(7.0)$ & $8.2(7.6)$ & 0.0001 \\
Anthropometrics & & & & & \\
Age (years) & $49.5(7.3)$ & $49.0(7.1)$ & $50.2(7.0)$ & $51.7(7.2)$ & 0.0001 \\
Height (cm) & $170.9(7.8)$ & $170.0(6.4)$ & $169.3(6.3)$ & $168.1(6.3)$ & 0.0001 \\
Weight (Kg) & $56.4(5.2)$ & $68.5(6.0)$ & $79.0(6.8)$ & $92.0(9.8)$ & 0.0001 \\
\hline
\end{tabular}

MUFA, monounsaturated fatty acids; PUFA, polyunsaturated fatty acids; SFA, saturated fatty acids.

* Sweets include sugar, honey, jam, chocolate, candy bars, paste, confetti/flakes, confectionery, ice-cream, cakes, pies, pastries, puddings and biscuits. 
Table 4 Multiple regression models for BMI as the dependent variable and dietary factors and other non-dietary factors as independent variables by sex

\begin{tabular}{|c|c|c|c|c|c|c|c|c|}
\hline \multirow[b]{2}{*}{ Model (\$) } & \multicolumn{4}{|c|}{ Women } & \multicolumn{4}{|c|}{ Men } \\
\hline & $\begin{array}{l}\text { Regression } \\
\text { coefficient }\end{array}$ & $\begin{array}{l}\text { Standard } \\
\text { error }\end{array}$ & $\begin{array}{c}p \\
\text { value }\end{array}$ & $r^{2}$ & $\begin{array}{l}\text { Regression } \\
\text { coefficient }\end{array}$ & $\begin{array}{l}\text { Standard } \\
\text { error }\end{array}$ & $\begin{array}{c}p \\
\text { value }\end{array}$ & $r^{2}$ \\
\hline $\begin{array}{l}\text { Model } 1 \text { (no diet + SFA + MUFA + PUFA + no fat) } \\
\text { Non-dietary variables* }\end{array}$ & & & 0.0000 & $\begin{array}{l}0.2100 \\
0.2060\end{array}$ & & & 0.0001 & $\begin{array}{l}0.0672 \\
0.0581\end{array}$ \\
\hline SFA (\% energy) & -0.0382 & 0.0088 & 0.0001 & 0.0007 & -0.0151 & 0.0102 & 0.1399 & 0.0001 \\
\hline MUFA (\% energy) & 0.0368 & 0.0076 & 0.0001 & 0.0004 & 0.0763 & 0.0078 & 0.0001 & 0.0047 \\
\hline PUFA (\% energy) & 0.1040 & 0.0110 & 0.0001 & 0.0029 & 0.0942 & 0.0110 & 0.0001 & 0.0043 \\
\hline Model 2 (no diet + fat + no fat $)$ & & & 0.0000 & 0.2064 & & & 0.0001 & 0.0638 \\
\hline Non-dietary variables* ${ }^{*}$ & & & & 0.2060 & & & & 0.0582 \\
\hline Fat (\% energy) & 0.0156 & 0.0045 & 0.0006 & 0.0004 & 0.0455 & 0.0046 & 0.0001 & 0.0056 \\
\hline $\begin{array}{l}\text { Model } 3 \text { (no diet }+ \text { carbohydrate }+ \text { no carbohydrate) }_{\text {Non-dietary variables* }}\end{array}$ & & & 0.0000 & $\begin{array}{l}0.2092 \\
0.2066\end{array}$ & & & 0.0001 & $\begin{array}{l}0.0758 \\
0.0588\end{array}$ \\
\hline Carbohydrate (\% energy) & -0.0380 & 0.0040 & 0.0001 & 0.0026 & -0.0612 & 0.0036 & 0.0001 & 0.0170 \\
\hline $\begin{array}{l}\text { Model } 4 \text { (no diet + olive oil + other fats + no fat) } \\
\text { Non-dietary variables* }\end{array}$ & & & 0.0000 & $\begin{array}{l}0.2065 \\
0.2060\end{array}$ & & & 0.0001 & $\begin{array}{l}0.0637 \\
0.0610\end{array}$ \\
\hline Olive oil (\% energy) & 0.0101 & 0.0060 & 0.0924 & 0.0001 & 0.0441 & 0.0060 & 0.0001 & 0.0027 \\
\hline Other fats (\% energy) & 0.0173 & 0.0047 & 0.0002 & 0.0004 & 0.0459 & 0.0047 & 0.0001 & 0.0031 \\
\hline
\end{tabular}

All models include intercept.

${ }^{*}$ Non-dietary variables are age, housework, sport, other leisure activities, work activity, smoking and education level. For women, also menopause and parity.

Table 5 Ratio (\%) energy intake/energy requirement by obesity level and sex

\begin{tabular}{lcr}
\hline & Women, & $\begin{array}{c}\text { Men, } \\
\text { mean (SD) }\end{array}$ \\
\hline Underweight & $110.35(31.72)$ & $126.99(33.46)$ \\
Normal & $102.51(28.99)$ & $109.80(28.44)$ \\
Overweight & $91.92(26.34)$ & $101.22(26.87)$ \\
Obese & $82.49(26.02)$ & $94.50(27.86)$ \\
\hline
\end{tabular}

and it was suggested that this may indicate greater measurement error among the independent variables in men (for example in the assessment of dietary intake) or that there are different, unmeasured predictors (e.g. metabolic rate) that are more operative than ingested energy intake and physical activity for men than for women.

Several potential sources of error and bias are possible in our study and should be considered in the interpretation of results. Obesity is an excess of adipose tissue, but direct measurement of adipose tissue mass in large epidemiological studies is impractical because of the high cost. As an indicator of obesity we used BMI, which is easy to assess and is considered to give a reliable average body fat estimate in spite of some limitations ${ }^{37,38}$.

One limitation of our study is its cross-sectional design. In this type of study the effect (obesity) and the potential causes (dietary fat and others factors) are measured simultaneously. This means that it is not possible to define a temporal sequence between diet and obesity. Only a non-directional relationship is possible ${ }^{11}$. In addition our study was based on a non-representative sample of the general population. However, the number of subjects was very large, the participation rate was relatively high, subjects came from different social levels and different geographical areas, and the pattern of dietary intake was very similar to that observed in surveys carried out in the same areas in representative samples of the Spanish population ${ }^{5}$.

Another important limitation is that information on diet is based on reported diet and assumes that the obese reported their diet as precisely as the non-obese. Several studies have shown that obese subjects underreport dietary intake ${ }^{39-43}$, but other studies ${ }^{44-46}$ suggest that information from obese subjects may be as valid and reproducible as that from non-obese subjects. Furthermore, the percentage of energy from fat seems to be less sensitive than total fat intake to this type of bias ${ }^{47}$.

Level of underreporting of habitual intake is known to be different according to the dietary assessment method used $^{47}$. In our study we used the diet history method which has been shown to be the least affected by underestimation of energy intake ${ }^{46}$. Furthermore, in the validation study ${ }^{23}$ correlation coefficients between the diet history and the referent method (mean of twelve 24-hour recalls), were between 0.69 and 0.89 for total fat, SFA, PUFA and MUFA. Nevertheless, in order to know the level of under- or overreporting of energy intake we estimated the ratio of EI : ER. According to our calculation, on the assumption that the coefficient of physical activity level is 1.55 , we observed in obese subjects an underestimation of $17.5 \%$ of energy intake in women but only $5.5 \%$ in men (Table 5). On the other hand, among underweight subjects, higher overreporting of energy was found more in men than in women. In order to calculate the ER, we used a standard coefficient of PAL for all groups of BMI, 
because the physical activity questionnaire used in the EPIC study was designed to rank subjects rather than to estimate individual energy expenditure from physical activity. Furthermore, we estimated the correlation coefficients between BMI and energy from fat only in subjects with 'normal' BMI (between 20.0 and $25.99 \mathrm{~kg} \mathrm{~m}^{2}$ ), where there does not seem to be an underestimation or overestimation of energy, and we found no association. The correlation coefficient was -0.03 in women and 0.003 in men.

The amount of adipose tissue is considered to be the result of the cumulative effect over time of energy intake from foods and energy expenditure (mainly physical activity and resting metabolism) ${ }^{6}$. If high energy and high fat intake are not important predictors of obesity, this means that, possibly, obese subjects are less physically active or they have a different metabolic rate. In conclusion, our study suggests that in a Mediterranean country with a high prevalence of obesity, where total energy and energy intake from fat is high, with high consumption of MUFA and olive oil, different types of dietary fat intake after adjusting for other non-dietary factors - are not important factors associated with obesity. However, because of the cross-sectional design and some level of underreporting of intake observed among obese subjects, bias cannot be entirely discarded.

\section{Acknowledgements}

EPIC is coordinated by the Unit of Nutrition and Cancer of the International Agency for Research on Cancer (IARC) (Agreement AEP/93/02). In Spain it receives financial support from the Europe Against Cancer Programme of the European Union (Agreement SOC 97200302 05F02), the Health Research Fund (FIS) of the Spanish Ministry of Health (Exp. 96-0032) and the participating regional governments. We thank Nadia Slimani from the Unit of Nutrition and Cancer (IARC) for her useful comments on the manuscript.

\section{References}

1 Stunkard AJ. Current views on obesity. Am. J. Med. 1996; 100: $230-6$

2 Seidell JC. Obesity in Europe: scaling and epidemic. Int. J. Obes. Relat. Metab. Disord. 1995; 19 (Suppl.): S1-4.

3 Seidell JC. The impact of obesity on health status: some implications for health care costs. Int. J. Obes. Relat. Metab. Disord. 1995; 19 (Suppl.): S13-16.

4 Quiles J, Vioque J. Prevalencia de obesidad en la Comunidad Valenciana. Med. Clin. (Barc.) 1996; 106: 529-33.

5 Grupo EPIC de España. Patrones de consumo y principales fuentes de ingesta de lípidos y ácidos grasos en la cohorte Española del Estudio Prospectivo Europeo sobre Dieta y Cancer (EPIC). Med. Clin. (Barc.) 1999; 112: 125-32.

6 Rosenbaum M, Leibel RL, Hirsch J. Obesity. N. Engl. J. Med. 1997; 337(6): 396-407.

7 Prentice AM, Jebb SA. Obesity in Britain: gluttony or sloth? BMJ 1995; 311: 437-9.
8 Ley CJ, Lees B, Stevenson JC. Sex- and menopauseassociated changes in body-fat distribution. Am. J. Clin. Nutr. 1992; 55: 950-4.

9 Astrup A, Toubro S, Raben A, Skov AR. The role of low-fat diets and fat substitutes in body weight management: what have we learned from clinical studies? J. Am. Diet. Assoc. 1997; 97 (Suppl. 7): S82-7.

10 Rolls BJ, Bell EA, Castellanos VH, Chow M, Pelkman CL, Thorwart ML. Energy density but not fat content of foods affected energy intake in lean and obese women. Am. J. Clin. Nutr. 1999; 69: 863-71.

11 Lissner L, Heitmann BL. Dietary fat and obesity: evidence from epidemiology. Eur. J. Clin. Nutr. 1995; 49: 79-90.

12 Seidell J. Dietary fat and obesity: an epidemiological perspective. Am. J. Clin. Nutr. 1998; 67 (Suppl.): S546-50.

13 Willett W. Is dietary fat a major determinant of body fat? $\mathrm{Am}$. J. Clin. Nutr. 1998; 67 (Suppl.): S556-62.

14 Bray G, Popkin B. Dietary fat intake does affect obesity! Am. J. Clin. Nutr. 1998; 68: 1157-73.

15 Willett W. Dietary fat and obesity: an unconvincing relation. Am.J. Clin. Nutr. 1998; 68: 1149-50.

16 Lissner L, Heitmann BL. The dietary fat : carbohydrate ratio in relation to body weight. Curr. Opin. Lipidol. 1995; 6(1): 8-13.

17 Katan MB, Grundy SM, Willet WC. Beyond low-fats diet. Clinical debate. N. Engl. J. Med 1997; 337(8): 563-6.

18 Shimomura Y, Tamura T, Suzuki M. Effect of dietary polyunsaturated fats on body fat accumulation. In: Romsos DR, et al., eds. Obesity: Dietary Factors and Controls. Tokyo: Japanese Science Society Press and Basel: Karger, 1991; 191-8.

19 Colditz GA, Willett WC, Stampfer MJ, London SJ, Segal MR, Speizer FE. Patterns of weight change and their relation to diet in a cohort of healthy women. Am. J. Clin. Nutr. 1990; 51: $1100-5$.

20 Riboli E, Kaaks R. The EPIC project: rationale and study design. Int. J. Epidemiol. 1997; 26 (Suppl.): S6-14.

21 Burke BS. The dietary history as a tool in research. J. Am. Diet. Assoc. 1947; 23: 104-11.

22 EPIC group of Spain. Validity and reproducibility of a diet history questionnaire in Spain (I. Foods). Int. J. Epidemiol. 1997; 26 (Suppl.1): S91-9.

23 EPIC group of Spain. Validity and reproducibility of a diet history questionnaire in Spain (II. Nutrients). Int. J. Epidemiol. 1997; 26 (Suppl. 1): S100-9.

24 EPIC group of Spain. Validity and reproducibility of a diet history questionnaire in Spain (III. Biochemical markers). Int. J. Epidemiol. 1997; 26 (Suppl. 1): S110-17.

25 Slimani N, Torrent M, Farriol N, et al. European Prospective Investigation into Cancer and Nutrition (EPIC): Food Composition Tables - Spain. Lyon, France: International Agency for Research on Cancer, 1991.

26 Lohman TG, Roche AF, Martorell R, eds. Anthropometric Standardization Reference Manual, 1st edn. Champaign, IL: Human Kinetics Publishers, 1988.

27 Pols MA, Peeters PHM, Ocké MC, et al. Estimation of reproducibility and relative validity of the questions included in the EPIC physical activity questionnaire. Int. J. Epidemiol. 1997; 26 (Suppl. 1): S181-9.

28 Schofield WN. Predicting basal metabolic rate, new standards and review of previous work. Hum. Nutr. Clin. Nutr. 1985; 39C (Suppl. 1): 5-41.

29 Dreon DM, Frey-Hewitt B, Ellsworth N, Williams PT, Terry RB, Wood PD. Dietary fat: carbohydrate ratio and obesity in middle-aged men. Am. J. Clin. Nutr. 1988; 47: 995-1000.

30 Romieu I, Willett WC, Stampfer MJ, et al. Energy intake and other determinants of relative weight. Am. J. Clin. Nutr. 1988; 47: 406-12.

31 Tucker LA, Kano MJ. Dietary fat and body fat: a multivariate 
study of 205 adult females. Am. J. Clin. Nutr. 1992; 56: 61622.

32 Slattery ML, McDonald A, Bild DE, Caan BJ, Hilner JE. Associations of body fat and its distribution with dietary intake, physical activity, alcohol, and smoking in blacks and whites. Am. J. Clin. Nutr. 1992; 55: 943-9.

33 Tremblay A, Plourde G, Després JP, Bouchard C. Impact of dietary fat content and fat oxidation on energy intake in humans. Am.J. Clin. Nutr. 1989; 49: 799-805.

34 George V, Tremblay A, Després JP, Leblanc C, Bouchard C. Effect of dietary fat content of total and regional adiposity in men and women. Int. J. Obes. 1990; 14: 1085-94.

35 Miller WC, Lindeman AK, Wallace J, Niederpruem M. Diet composition, energy intake, and exercise in relation to body fat in men and women. Am. J. Clin. Nutr. 1990; 52: 426-30.

36 Klesges RC, Klesges LM, Haddock CK, Eck LH. A longitudinal analysis of the impact of dietary intake and physical activity on weight change in adults. Am. J. Clin. Nutr. 1992; 55: 818-22.

37 Garn SM, Leonard WR, Hawthorne VM. Three limitations of body mass index. Am. J. Clin. Nutr. 1986; 44: 996-7.

38 Heitmann BL. Evaluation of body fat estimated from body mass index, skinfolds and impedance. A comparative study. Eur. J. Clin. Nutr. 1990; 44(11): 831-7.

39 Hultén B, Bengtsson C, Issaksson B. Some errors inherent in a longitudinal dietary survey revealed by the urine nitrogen test. Eur. J. Clin. Nutr. 1990; 44: 169-74.

40 Heitmann BL. The influence of fatness, weight change, slimming history and other variables on diet reporting in
Danish men and women aged 35-65 years. Int. J. Obes. 1993; 17: 329-36.

41 Heitmann B, Lissner L. Dietary underreporting by obese individuals - is it specific or non-specific? BMJ 1995; 311: 986-9.

42 Pryer JA, Vrijheid M, Nichols R, Kiggins M, Elliott P. Who are the 'low energy reporters' in the Dietary and Nutritional Survey of British Adults? Int. J. Epidemiol. 1997; 26: 146-54.

43 Heerstrass DW, Ocké MC, Bueno-de-Mesquita HB, Peeters PHM, Seidell JC. Underreporting of energy, protein and potassium intake in relation to body mass index. Int. $J$. Epidemiol. 1998; 27: 186-93.

44 Myers RJ, Klesges RC, Eck LH, Hanson CL, Klem ML. Accuracy of self-reports of food intake in obese and normalweight individuals: effects of obesity on self-reports of dietary intake in adult females. Am. J. Clin. Nutr. 1988; 48: $1248-51$.

45 Lissner L, Habicht J-P, Strupp BJ, Levistky DA, Haas JD, Roe DA. Body composition and energy intake: do overweight women overeat and underreport? Am. J. Clin. Nutr. 1989; 49: $320-5$.

46 Lindroos A-K, Sjöström L, Lissner L. Validity and reproducibility of a self-administered dietary questionnaire in obese and non-obese subjects. Eur.J. Clin. Nutr. 1993; 47: 461-71.

47 Black AE, Goldberg GR, Jebb SA, Livingstone MBE, Cole TJ, Prentice AM. Critical evaluation of energy intake data using fundamental principles of energy physiology: 2. Evaluating the results of published surveys. Eur. J. Clin. Nutr. 1991; 45 583-99. 